\title{
Author Correction: Harnessing the diversity of small-scale actors is key to the future of aquatic food systems
}

Rebecca E. Short (1), Stefan Gelcich (1), David C. Little (D), Fiorenza Micheli(D), Edward H. Allison (1), Xavier Basurto (1),

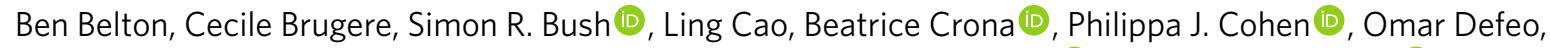

Peter Edwards, Caroline E. Ferguson, Nicole Franz, Christopher D. Golden (D), Benjamin S. Halpern (D), Lucie Hazen, Christina Hicks (1), Derek Johnson (10), Alexander M. Kaminski (1), Sangeeta Mangubhai, Rosamond L. Naylor (1),

Melba Reantaso, U. Rashid Sumaila (D), Shakuntala H. Thilsted, Michelle Tigchelaar $\mathbb{D}^{\mathbb{D}}$, Colette C. C. Wabnitz $\mathbb{D}^{\mathbb{D}}$ and Wenbo Zhang (10)

Correction to: Nature Food https://doi.org/10.1038/s43016-021-00363-0, published online 15 September 2021.

In the version of this Analysis initially published, there was an error in the affiliation listed for Alexander M. Kaminski (mistakenly appearing as Pontificia Universidad Catolica de Chile). Kaminski's correct affiliation is at the Institute of Aquaculture, University of Stirling, Stirling, UK. The change has been made to the online version of the article.

Published online: 4 October 2021

https://doi.org/10.1038/s43016-021-00396-5

(c) The Author(s), under exclusive licence to Springer Nature Limited 2021 